\title{
Inter-Subshell Break in the Lattice Enthalpies of First-Row Transition-Metal Trichlorides
}

\author{
${ }^{* 1}$ Peter G. Nelson, ${ }^{2}$ David A. Johnson \\ ${ }^{* 1}$ Department of Chemistry, University of Hull, Hull HU6 7RX, UK \\ ${ }^{2}$ Department of Chemistry, The Open University, Milton Keynes MK7 6AA, UK \\ p.g.nelson@hull.ac.uk
}

Abstract: Lattice enthalpies of first-row transition-metal trichlorides $\left(\mathrm{MCl}_{3}\right)$ are assembled and analysed. Subtraction of the various ligand-field contributions to these gives a smooth curve through the points for $3 d^{1}-3 d^{10}$ ions, but leaves a break of about $20 \mathrm{~kJ} \mathrm{~mol}^{-1}$ between $3 \mathrm{~d}^{0}$ (i.e. $3 \mathrm{p}^{6}$ ) and $3 \mathrm{~d}^{1}$. This value is compared with that for $\mathrm{M}^{3+}(\mathrm{aq})$ and $\mathrm{K}_{3} \mathrm{MF}_{6}$.

Keywords: transition metal, trichloride, lattice enthalpy, ligand-field, inter-subshell break.

\section{INTRODUCTION}

In a series of papers, we have examined the variations in the enthalpies of the following processes across the first transition series [1-4]:

$\mathrm{M}^{2+}(\mathrm{g})+\mathrm{aq} \rightarrow \mathrm{M}^{2+}(\mathrm{aq})$

$\mathrm{M}^{2+}(\mathrm{g})+2 \mathrm{X}^{-}(\mathrm{g}) \rightarrow \mathrm{MX}_{2}(\mathrm{~s})(\mathrm{X}=\mathrm{F}, \mathrm{Cl}, \mathrm{I})$

$\mathrm{M}^{3+}(\mathrm{g})+\mathrm{aq} \rightarrow \mathrm{M}^{3+}(\mathrm{aq})$

$3 \mathrm{~K}^{+}(\mathrm{g})+\mathrm{M}^{3+}(\mathrm{g})+6 \mathrm{~F}^{-}(\mathrm{g}) \rightarrow \mathrm{K}_{3} \mathrm{MF}_{6}(\mathrm{~s})$

We found that the variations are fully accounted for if consideration is given to (1) the stabilization energy resulting from the splitting of the $3 \mathrm{~d}$ orbitals in the ligand field $\left(\Delta E_{\text {orb }}\right.$ ); (2) the loss of energy arising from the reduction of metal-ligand distance accompanying the stabilization (the energy of contraction against the force constant, $\Delta E_{\text {ctr }}$ ) [5]; (3) the irregular, stabilizing decrease in interelectronic repulsion energy, over and above the values for spherical ions, arising from the expansion of the $3 \mathrm{~d}$ shell in the ligand field (the 'nephelauxetic' effect) $\left(\Delta E_{\text {rep-irreg }}\right)$ [6]; and (4) the reduction in spin-orbit coupling energy associated with the splitting of the $3 \mathrm{~d}$ orbitals $\left(\Delta E_{\mathrm{so}}\right)$. When these quantities (per mole) are subtracted from the enthalpies of the above reactions, smooth curves are obtained through the points for $3 \mathrm{~d}^{1}$ to $3 \mathrm{~d}^{10}$ ions (see, e.g., Fig. 1).

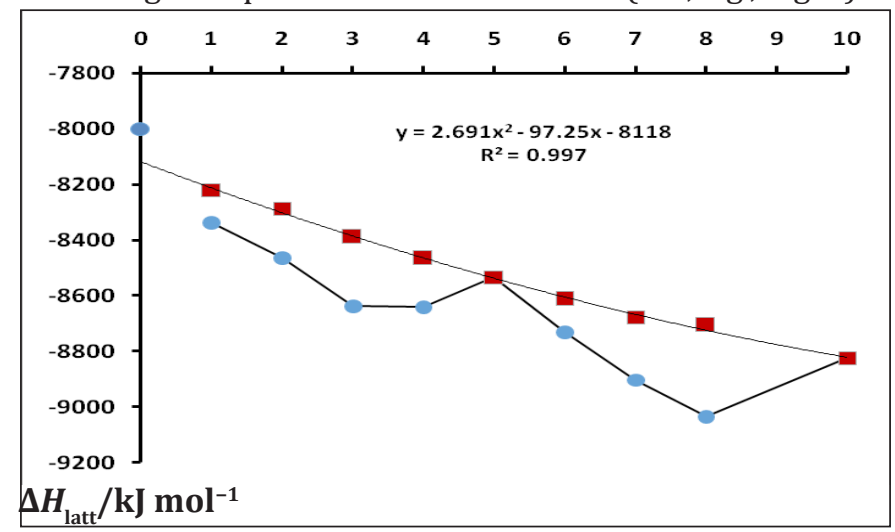

Fig1. Lattice enthalpies of $K_{3} M F_{6}$ plotted against number of $3 d$ electrons. Blue circles, experimental values; red squares, residual values after subtracting the energies listed in the text. Data from ref. 1 . The equation and correlation factor refer to the residual curve.

www.arjonline.org

Page 37 
Inter-Subshell Break in the Lattice Enthalpies of First-Row Transition-Metal Trichlorides

This analysis revealed an unexpected feature. Previous and long-standing ligand field treatments of such problems $[7,8]$ had assumed the existence of a smooth baseline from $3 \mathrm{~d}^{0}$ to $3 \mathrm{~d}^{10}$. Ours revealed a discontinuity between the values for $3 \mathrm{~d}^{0}$ and $3 \mathrm{~d}^{1}$. Since $3 \mathrm{~d}^{0}$ is actually $3 \mathrm{p}^{6}$, this amounts to an inter-subshell break. The magnitude of this break varies as shown in Table 1. For $\mathrm{M}^{2+}$ ions, the values are in the order $\left(\mathrm{aq}, \mathrm{F}^{-}\right)<\mathrm{Cl}^{-}<\mathrm{I}^{-}$, for $\mathrm{M}^{3+}$ ions, aq $<\mathrm{F}^{-}$, and comparing $\mathrm{M}^{3+}$ ions with $\mathrm{M}^{2+}$ ions, $\mathrm{M}^{3+}>\mathrm{M}^{2+}$. These sequences follow approximately the nephelauxetic order for ligands and ions [9], which made us think that the inter-subshell break may be related to the nephelauxetic effect. To test this hypothesis, we have extended our analysis to the trichlorides, for which the nephelauxetic effect is greater than for $\mathrm{M}^{3+}(\mathrm{aq})$ and $\mathrm{K}_{3} \mathrm{MF}_{6}(\mathrm{~s})$.

Table 1. Inter-subshell breaks $\left(/ \mathrm{kJ} \mathrm{mol}^{-1}\right)$

\begin{tabular}{|c|c|c|}
\hline Species & Break & Ref. \\
\hline $\mathrm{M}^{2+}(\mathrm{aq})$ & 10 & 2 \\
\hline $\mathrm{MF}_{2}(\mathrm{~s})$ & 0 & 3 \\
\hline $\mathrm{MCl}_{2}(\mathrm{~s})$ & 80 & 3 \\
\hline $\mathrm{MI}_{2}(\mathrm{~s})$ & 90 & 3 \\
\hline $\mathrm{M}^{3+}(\mathrm{aq})$ & 42 & 4 \\
\hline $\mathrm{K}_{3} \mathrm{MF}_{6}(\mathrm{~s})$ & 117 & See Fig. 1 \\
\hline
\end{tabular}

\section{Calculations and Results}

We have analysed the enthalpy of the process

$\mathrm{M}^{3+}(\mathrm{g})+3 \mathrm{Cl}^{-}(\mathrm{g}) \rightarrow \mathrm{MCl}_{3}(\mathrm{~s})$

in the same way as in our previous studies using the data in Table 2. The results are set out in Table 3 and plotted in Fig 2. A complication is that the experimental value for gallium trichloride is for tetrahedral coordination whereas all the other trichlorides have octahedral structures. To allow for this, we have estimated the enthalpy of transition to the octahedral form to be about $10 \pm 10 \mathrm{~kJ} \mathrm{~mol}^{-1}$. The low value reflects the fact that weak bonds in the structure complete a distorted octahedron [10]. Comparison between the lattice enthalpies of the trichlorides and corresponding trifluorides also suggest a low value [11]. The uncertainty does not significantly affect the extrapolation to $3 \mathrm{~d}^{0}$, which gives an inter-subshell break of $24 \pm 10 \mathrm{~kJ} \mathrm{~mol}{ }^{-1}$. This is less than for $\mathrm{M}^{3+}(\mathrm{aq})$ and $\mathrm{K}_{3} \mathrm{MF}_{6}(\mathrm{~s})$, contrary to our expectations. The inter-subshell break is not therefore related to the nephelauxetic effect, and must have another origin.

Table2. Data used in the calculations ${ }^{a}$

\begin{tabular}{|c|c|c|c|c|c|c|}
\hline Trichloride & Config. & $\boldsymbol{\Delta} \boldsymbol{H}_{\mathrm{f}}^{\circ}$ & $\boldsymbol{r}$ & $\boldsymbol{\Delta}$ & $\boldsymbol{B}$ \\
\hline $\mathrm{ScCl}_{3}[6]^{b}$ & $3 \mathrm{~d}^{0}$ & $-945^{c} \pm 2$ & $258^{j}$ & & \\
\hline $\mathrm{TiCl}_{3}[6]$ & $3 \mathrm{~d}^{1}$ & $-722^{d} \pm 5$ & $247^{j}$ & $12,900^{o, p}$ & & \\
\hline $\mathrm{VCl}_{3}[6]$ & $3 \mathrm{~d}^{2}$ & $-584^{e} \pm 3$ & $245^{j}$ & $13,900^{o}$ & $563^{o}$ & $550^{o, q}$ \\
\hline $\mathrm{CrCl}_{3}[6]$ & $3 \mathrm{~d}^{3}$ & $-544^{f} \pm 2$ & $234.3^{k}$ & $13,700^{o, q}$ & $3400^{o, q}$ \\
\hline $\mathrm{FeCl}_{3}[6]$ & $3 \mathrm{~d}^{5}$ & $-396^{g} \pm 2$ & $235.9^{l}$ & & & \\
\hline $\mathrm{GaCl}_{3}[4]$ & $3 \mathrm{~d}^{10}$ & $-525^{h} \pm 10$ & $220^{m}$ & & & \\
\hline$-[-[6]$ & & $(-515 \pm 15)^{i}$ & $(232)^{n}$ & & & \\
\hline
\end{tabular}


Inter-Subshell Break in the Lattice Enthalpies of First-Row Transition-Metal Trichlorides

${ }^{a}$ Column 3, enthalpy of formation at $25{ }^{\circ} \mathrm{C}\left(/ \mathrm{kJ} \mathrm{mol}^{-1}\right)$; col. 4, M-Cl distance (/pm); col. 5, ligand-field splitting $\left(/ \mathrm{cm}^{-1}\right)$; cols. 5 and 6 , interelectronic repulsion parameters $\left(/ \mathrm{cm}^{-1}\right)$. Other data from refs. $1-4$ and in footnotes to Table 3. ${ }^{b}$ Coordination number of metal ion. ${ }^{c}$ J.M. Stuve, U.S. Bur. Mines Rep. Invest. 6705, 1965; M.Yu. Furkalyuk, V.Ya. Leonidov, and V.F. Goryushkin, Russ. J. Phys. Chem., 1995, 69, 2029. ${ }^{d}$ M.W. Chase, C.A. Davies, J.R. Downey, D.J. Fruip, R.A. McDonald, and A.N. Syverud, JANAF Thermochemical Tables, 3rd edn, American Institute of Physics, New York, 1986. ${ }^{e}$ Calculated from data of R.V. Mrazek, D.W. Richardson, H.O. Poppleton, and F.E. Block, U.S. Bur. Mines Rep. Invest. 7096, 1968, and E.G. Lavut and N.V. Chelovskaya, J. Chem. Thermodynamics, 1989, 21, 765; ${ }^{f}$ J.W. Ball and D.K. Nordstrom, J. Chem. Eng. Data, 1998, 43, 895. ${ }^{g}$ V.B. Parker

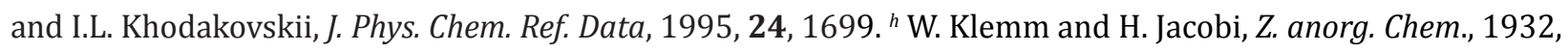
207, 177. ${ }^{i}$ Estimated (see text). ${ }^{j}$ W. Klemm and E. Krose, Z. anorg. Chem., 1947, 253, 218. ${ }^{k}$ B. Morosin and A. Narath, J. Chem. Phys., 1964, 40, 1958. ' J.W. Cable, M.K. Wilkinson, E.O. Wollan, and W.C. Koehler, Phys. Rev., 1962, 127, 714. ${ }^{m}$ Ref. 10. ${ }^{n}$ Estimated by comparison with aqua ions and fluorides (refs. 1 and 4). ${ }^{o}$ R.J.H. Clark, J. Chem. Soc., 1964, 417. ${ }^{p}$ F. Cavallone, I. Pollini, and G. Spinolo, Phys. Stat. Sol., 1971, 45b, 405. ${ }^{q}$ D.L. Wood, J. Ferguson, K. Knox, and J.F. Dillon, Jr., J. Chem. Phys., 1963, 39, 890.

Table3. Results of calculations $\left(/ \mathrm{kJ} \mathrm{mol}^{-1}\right)^{a}$

\begin{tabular}{|c|c|c|c|c|c|c|}
\hline Trichloride & $\boldsymbol{\Delta} \boldsymbol{H}_{\text {latt }}$ & $\boldsymbol{\Delta} \boldsymbol{E}_{\text {orb }}$ & $\boldsymbol{\Delta} \boldsymbol{E}_{\text {rep-irreg }}$ & $\boldsymbol{\Delta} \boldsymbol{E}_{\text {ctr }}$ & $\boldsymbol{\Delta} \boldsymbol{E}_{\text {so }}$ & $\boldsymbol{\Delta} \boldsymbol{H}_{\text {res }}$ \\
\hline $\mathrm{ScCl}_{3}$ & -4895 & 0 & 0 & 0 & 0 & -4895 \\
\hline $\mathrm{TiCl}_{3}$ & -5132 & -62 & $(-37)^{b}$ & $5^{c}$ & $2^{d}$ & -5040 \\
\hline $\mathrm{VCl}_{3}$ & -5308 & -120 & $(-48)^{b}$ & $5^{c}$ & $3^{d}$ & -5148 \\
\hline $\mathrm{CrCl}_{3}$ & -5490 & -197 & -41 & $22^{c}$ & $5^{e}$ & -5279 \\
\hline $\mathrm{FeCl}_{3}$ & -5409 & 0 & 0 & 0 & 0 & -5409 \\
\hline $\mathrm{GaCl}_{3}[6]$ & -5625 & 0 & 0 & 0 & 0 & -5625 \\
\hline
\end{tabular}

${ }^{a}$ Col. 2, enthalpy of formation from ions (lattice enthalpy); col. 3, orbital stabilization energy; col. 4, nephelauxetic stabilization energy; col. 5, contraction energy; col. 6, spin-orbit coupling energy loss; col.7, residual enthalpy (lattice enthalpy minus energies in cols. 2-6). ${ }^{b}$ Estimated by scaling the values for aqua ions and fluorides (refs. 1 and 4) according to the value for $\mathrm{CrCl}_{3}{ }^{\circ}$ Calculated from a value of about $300 \mathrm{~cm}^{-1}$ for the wave number of the symmetric vibration of the $\left[\mathrm{MCl}_{6}\right]$ coordination entity in $\mathrm{MCl}_{3}$, estimated from the values for discrete $\left[\mathrm{MCl}_{6}\right]^{3-}$ ions (K. Nakamoto, Infrared and Raman Spectra of Inorganic and Coordination Compounds, 5th edn., Part A, Table II-8a, Wiley, New York, 1997; H.H. Eysel, Z. anorg. Chem., 1972, 390, 210). We have smoothed the experimental values of $\Delta r$ by comparison with the values for aqua ions and fluorides (refs. 1 and 4 ). ${ }^{d}$ Calculated from a Boltzmann distribution over the energy levels of gaseous $\mathrm{M}^{3+}$ (http://physics.nist.gov/asd) and of the ion in an octahedral environment (B.N. Figgis and M.A. Hitchman, Ligand Field Theory and Its Applications, 2nd edn., Wiley Inc. UK, 2000, pp. 241-251). The latter were calculated using $\lambda=a \lambda_{\text {gas }}$ with $\lambda_{\text {gas }}$ from Figgis and Hitchman (op. cit., pp. 107-110) and $a=0.6$ as for $\mathrm{CrCl}_{3}$ (Table 2, note $q$ ). ${ }^{e}$ Calculated from the energy levels of the gaseous ion. To a first approximation, the ${ }^{4} \mathrm{~A}_{2 \mathrm{~g}}$ ground state does not split in an octahedral field. 


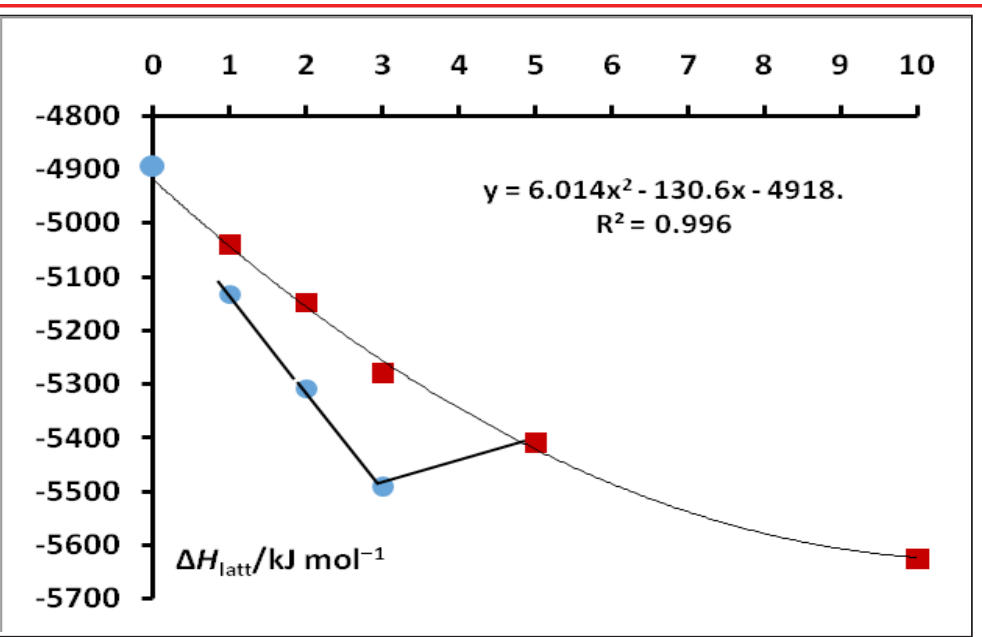

Fig 2. Lattice enthalpies of trichlorides plotted against number of $3 d$ electrons. Blue circles, experimental values; red squares, residual values after subtracting the energies listed in the text (Table 3). The equation and correlation factor refer to the residual curve.

\section{REFERENCES}

1. D.A. Johnson and P.G. Nelson, Inorg. Chem., 1995, 34, 3253.

2. D.A. Johnson and P.G. Nelson, Inorg. Chem., 1995, 34, 5666.

3. D.A. Johnson and P.G. Nelson, J. Chem. Soc. Dalton Trans., 1995, 3483.

4. D.A. Johnson and P.G. Nelson, Inorg. Chem., 1999, 38, 4949.

5. In previous papers, we called this the 'relaxation' energy $\left(\Delta E_{\mathrm{rl} x}\right)$, but this better describes the reverse process.

6. Note that this has a value for $3 d^{1}$ ions even though there is no $3 d-3 d$ repulsion in the gaseous ion. This is because there is repulsion in the spherical ion (1/5th of that in $3 \mathrm{~d}^{5}$ and $1 / 10$ th of that in $\left.3 \mathrm{~d}^{10}\right)$, and hence in the energy of the gaseous ion relative to the spherical ion. The nephelauxetic effect brings down the energy of the spherical ion towards that of the gaseous ion.

7. W.G. Penney, Trans. Faraday Soc. 1940, 36,627.

8. P. George and D.S. McClure, Prog. Inorg. Chem.,1959, 1, 381.

9. C.E. Schäffer and C.K. Jørgensen, J. Inorg. Nuclear Chem., 1958, 8, 143.

10. C. Lustig and N.W. Mitzel, Z. Naturforsch., 2004, 59b, 140.

11. All the trifluorides, including $\mathrm{GaF}_{3}$, have an octahedral structure, enabling an approximate value for octahedral $\mathrm{GaCl}_{3}$ to be obtained from a plot of the lattice enthalpies of the trichlorides against the trifluorides.

Citation: Peter G. Nelson, David A. Johnson "Inter-Subshell Break in the Lattice Enthalpies of First-Row Transition-Metal Trichlorides". American Research Journal of Chemistry, 1(1); pp:37-40.

Copyright (c) Peter G. Nelson, David A. Johnson, This is an open access article distributed under the Creative Commons Attribution License, which permits unrestricted use, distribution, and reproduction in any medium, provided the original work is properly cited. 